\title{
From Superantigens to "Real" Viral Antigens
}

\author{
Marcia A. Blackman
}

\begin{abstract}
Studies inspired by Dr. Peter Doherty led to over 16 years of research into the mouse gamma-herpesvirus, $\gamma \mathrm{HV} 68$, in the Blackman laboratory. Progress on our understanding of $\gamma \mathrm{HV} 68$ biology include insight into the establishment of latency, immune control of the acute and latent stages of infection and experimental vaccines, is described here.
\end{abstract}

Keywords: $\gamma$-herpesvirus, $\gamma$ HV68, latency

$\mathbf{P}$ ROBABLY THE BEST career decision I ever made was to accept a position in Peter Doherty's department at St. Jude Children's Research Hospital. It was my first "real" job after my postdoc and I planned to continue my postdoctoral studies by using "superantigens" to study peripheral immune tolerance. Superantigens were well suited for the project because they stimulate $\mathrm{T}$ cells expressing specific $\mathrm{T}$ cell receptor $\mathrm{V} \beta$ elements, making it possible to track $\mathrm{T}$ cells of known specificity during thymic selection. To be honest, Peter was never very enthusiastic about this project and gently pushed me to the study of, to quote Peter, "real" antigens, that is, viral antigens.

\section{Does $\gamma \mathrm{HV} 68$ Contain a Viral Superantigen?}

My transition from studying superantigens to viral antigens began because of a collaboration with Peter who was triggered by his developing interest in a mouse gammaherpesvirus, murine $\gamma$-herpesvirus-68 or $\gamma \mathrm{HV} 68$, arguably a mouse model for Epstein Barr virus (EBV). Peter's laboratory had discovered that infection of mice with $\gamma \mathrm{HV} 68$ led to the activation of CD8 T cells, similar to that observed during infectious mononucleosis following EBV infection of humans. Interestingly (for me), this CD8 T cell response after $\gamma \mathrm{HV} 68$ infection was strongly biased toward $\mathrm{T}$ cells expressing a $\mathrm{V} \beta 4 \mathrm{~T}$ cell receptor, raising the intriguing possibility that $\gamma \mathrm{HV} 68$ expressed a superantigen (35). My group subsequently published several articles on the intriguing $\mathrm{V} \beta 4$ response, speculating that it might be induced by a viral superantigen that was presented by latently infected, activated B cells elicited by $\gamma \mathrm{HV} 68$ infection $(4,9,18-20)$. The data for this were strong. TCR CDR3 (spectratype) analysis showed that the expanded CD8 T cells were clonal or oligoclonal populations. Although the populations were largely unique in individual mice, there was some evidence for shared "public" populations between individual mice (20). Further- more, although the stimulation was major histocompatibility complex (MHC)-independent (4,35), the magnitude of the response was somehow influenced by both MHC and non-MHC genes (19). Indeed, we identified two quantitative trait loci associated with the activation of $\mathrm{V} \beta 4 \mathrm{~T}$ cells - one located on chromosome 17, near or proximal to the $\mathrm{MHC} \mathrm{H} 2$ locus, and the other located on chromosome 6 in a region that spans the TCR and CD8 (Tcrb and Cd8a) loci. We also showed that CD4 T cells were required for the activation of $\mathrm{V} \beta 4 \mathrm{CD} 8 \mathrm{~T}$ cells (9). Although our accumulating data were consistent with the induction of a superantigen-like ligand in latently infected, activated B cells, it was Sam Speck's group who subsequently identified the viral superantigen as secreted M1, the gene responsible for the inhibition of viral recrudescence (5). In the meantime, I had moved on from studying the putative viral superantigen and was becoming a bona fide viral immunologist, trying to understand immunity generated toward $\gamma \mathrm{HV} 68$ - to understand how the virus could evade immunity and establish lifelong latency with a view to developing prophylactic vaccines.

\section{yHV68-A Mouse Model for EBV and Kaposi's Sarcoma-Associated Herpesvirus}

The $\gamma$-herpesviruses initially establish a lytic infection in their respective hosts. Although this acute infection is cleared, the virus sneaks through and establishes latency, which persists for the life of the host. The virus is normally maintained in a quiescent state in an immunocompetent host but can recrudesce if the host's immune system is suppressed for some reason. In the human, this can result in a variety of malignancies, including Burkett's lymphoma, Hodgkin's disease, nasopharyngeal carcinoma, B cell lymphoproliferative syndromes, and Kaposi's sarcoma. The $\gamma$-herpesviruses are tightly species-specific, so there is no mouse model for the

Trudeau Institute, Saranac Lake, New York.

(C) Marcia A. Blackman, 2020; Published by Mary Ann Liebert, Inc. This Open Access article is distributed under the terms of the Creative Commons Attribution Noncommercial License (http://creativecommons.org/licenses/by-nc/4.0/) which permits any noncommercial use, distribution, and reproduction in any medium, provided the original author(s) and the source are cited. 
human $\gamma$-herpesviruses, which include EBV and Kaposi's sarcoma-associated herpesvirus (KSHV). The murine $\gamma$ herpesvirus-68 shares many biological features and sequence homologies with EBV and KSHV $(30,38)$ and therefore provides an important animal model where host/virus interactions can be dissected in vivo. Thus, with Peter's encouragement, my laboratory started studying the mouse $\gamma$-herpesvirus in earnest, and, over the ensuing years, learned a great deal about the immunology of latent viral infections in general.

\section{Establishment of Latency}

Our initial studies focused on understanding when, and in what cell types, latency is established, and how long-term latency is maintained. We discovered that latency could be established in splenic macrophages, dendritic cells, and B cells - all three types of antigen-presenting cells (6), but that long-term latency is preferentially maintained in splenic germinal center and memory B cells (8). These data are consistent with $\gamma \mathrm{HV} 68$ exploiting the life cycle of the B cell for long-term maintenance, as has been shown for EBV $(32,34)$. Consistent with this, we found that the maintenance of long term $\gamma$-herpesvirus latency in B cells is dependent on the CD40-mediated development of memory B cells (25).

We also showed that latency was established almost immediately after infection and that latency could be established following infection with a replication-deficient mutant virus, indicating that viral replication was not required for the establishment of latency (7). This important finding indicated that viral latency could be disseminated by cellular proliferation, which had important implications for prophylactic vaccine development. We realized that the establishment of latency could not be prevented simply by reducing lytic infection but had to be specifically targeted at the site and time of the initial infection.

\section{Identification of a Latency-Associated Epitope and Lytic Epitopes}

To better understand the immune response to latency, it was essential to identify $\mathrm{T}$ cell epitopes expressed on latentlyinfected cells. A breakthrough came from collaborative studies with Jeff Sample, James Stewart, and David Woodland, where we identified a latency-associated CD8 epitope in the M2 protein $(21,28)$. CD8 T cells specific for the M2 epitope controlled the initial burst of latency early in infection, which raised the possibility that vaccination with $\mathrm{M} 2$ might be able to modulate the course of persistent infection (36).

Around the same time, we identified two epitopes in C57BL/6 mice (ORF61/K ${ }^{\mathrm{b}}$ and ORF6/D ${ }^{\mathrm{b}}$ ) associated with the lytic phase of infection (26). Interestingly, they were expressed at two distinct phases of viral infection-early (6 days postinfection) and later (18 days postinfection). Several years later, with the help of Sette and colleagues, we identified 31 more CD8 epitopes that also fell into the same two distinct patterns of expression (17), and we also identified 16 CD4 epitopes (11). The expression of CD4 T cell epitopes during $\gamma \mathrm{HV} 68$ infection could be divided into three phases: (i) expression during acute infection, (ii) expression both during the acute phase and the early stages of latency, and (iii) expression exclusively during latency, which was restricted to M2. These data, taken together with human studies showing that transferred CD4 T cells can develop into antitumor effectors $(31,41)$, illustrate the potential of CD4 T cells as therapy for $\gamma$-herpesvirus-associated tumors. With the identification of multiple lytic and latent epitopes, we had developed a powerful toolbox for dissecting $\mathrm{T}$ cell immune control of the lytic and latent phases of infection.

\section{Immune Control: CD8 and CD4 T Cells, Antibody}

Our early studies focused on $\mathrm{T}$ cell immune control of $\gamma$ HV68 lytic and latent infection. We showed that M2specific (latency-specific) CD8 T cells could modulate, but not prevent, the establishment of latency (36). Additional studies further addressed the mechanism of maintenance of CD8 T cells during latency (12). We showed that during long-term latency, naive $\mathrm{T}$ cells are recruited into the response in an epitope-specific manner and, interestingly, when virus reactivation is induced, recruitment of $\mathrm{T}$ cells for some, but not all, T cell epitopes is enhanced. In addition, the function of CD8 $\mathrm{T}$ cells newly recruited into the response is impaired. These data show unexpected complexity in the response of epitope-specific CD8 T cells during different stages of acute infection, latency, and reactivation.

Although an important role for CD4 T cells is to help the CD8 $\mathrm{T}$ cell response, virus-specific CD4 T cells also appeared to have a direct effector role, and we showed that CD4 T cells specific for gp $150_{67-83}$ and ORF $11_{168-180}$ epitopes were stimulated throughout latency, for as long as 6-8 months after infection (10). To address the role of CD4 T cells in more detail, we created a TCR transgenic mouse that expressed CD4 T cells specific for the gp150 epitope. This mouse model revealed that latently-infected dendritic cells and B cells stimulated virusspecific CD4 T cells, even during quiescent latency (13).

Although accumulating data indicated that $\mathrm{T}$ cells played a very important role in clearance of lytic virus after infection, and also immune control of latency, early studies had shown that the depletion of T cells in latently-infected mice did not trigger viral recrudescence, suggesting a role for humoral immunity $(24,33)$. Consistent with this, $\mathrm{T}$ cell depletion of antibody-deficient mice, but not antibodysufficient mice, triggered viral recrudescence. Furthermore, recrudescence could be prevented in these mice by passive transfer of immune serum, directly demonstrating an important role for antibody in controlling $\gamma$ HV68 latency (24). Antibody was not sufficient for controlling latency, however, as we later showed that in mice that had been depleted of $\mathrm{T}$ cells there was detectable de novo infection of $\mathrm{B}$ cells during $\gamma \mathrm{HV} 68$ latency, supporting the idea that viral reactivation occurred throughout latency (16).

\section{Can We Develop a Vaccine for the $\gamma$-Herpesviruses?}

Our T cell vaccination studies (39) showed that vaccination with dendritic cells pulsed with either MHC class Ior class II-restricted, lytic cycle $\mathrm{T}$ cell epitopes reduced the lung viral titers during acute infection and reduced the peak level of latency but had no effect on the long-term establishment and maintenance of latency (27). DNA vaccination with a plasmid encoding the $\mathrm{M} 2_{91-99} / \mathrm{K}^{\mathrm{d}}$ latency-associated epitope also failed to block the establishment of latency, and, as expected for a latent epitope vaccine, there was no effect on the acute phases of infection (37). T cell epitope vaccination strategies, therefore, failed to impact the longterm establishment of latency. 
Ting-Ting Wu and Ren Sun at the University of California at Los Angeles used the in vivo mouse $\gamma \mathrm{HV} 68$ model to obtain insight into gene expression during $\gamma \mathrm{HV}$ infection (29). They generated a recombinant AC-RTA (replication and transcription activator) $\gamma$ HV68 virus, which also had a deletion in three genes essential for latency (ORF72, M11, and ORF73). This resulted in a virus that could acutely infect mice but failed to establish latency (22). Importantly, AC-RTA induced protective immunity against subsequent infection with wild-type virus. These studies showed that live-attenuated viruses that fail to establish latency can initiate protection against the subsequent establishment of latency by wild-type virus. Analysis of the correlates of immune protection for AC-RTA showed that protective, sterilizing immunity required both $\mathrm{T}$ cells and antibody. Interestingly, antibody was required to protect the brain from lethal viral infection, raising important safety considerations for vaccine strategies based on live-attenuated viruses (15).

We also analyzed another mutant virus generated by the $\mathrm{Wu}$ and Sun group that had a block in late viral gene expression (termed ORF31STOP). Our key finding was that the route of infection with the mutant virus determined the anatomical site and persistence of latent infection (23). For example, i.p. infection induced strong cellular immunity and a nonneutralizing antibody response, and the mice had enhanced immune control of challenge infection, whereas intranasal vaccination was poorly immunogenic and mice were not protected.

Thus, the mouse $\gamma \mathrm{HV} 68$ model has great utility for the development and analysis of prophylactic vaccines (40). Experimental vaccines are still being developed and studied in the $\mathrm{Wu}$ laboratory.

\section{Other Studies}

We carried out a variety of other studies using $\gamma \mathrm{HV} 68$ as an in vivo model. First, we examined immune control of latency during aging, to test the hypothesis that loss of immune function of $\gamma$-herpesviruses during aging contributed to viral recrudescence and malignancy. Unexpectedly, we found that virus-specific CD8 $\mathrm{T}$ cell number and function did not decline with aging. In contrast, although viral titers were maintained, there was a progressive decline in neutralizing activity with age (42). Second, we followed up on a report that $\gamma \mathrm{HV} 68$ infection enhanced subsequent resistance to bacterial infections $(1,2)$ and showed that this resistance was transient $(43,44)$. Third, with Horwitz and colleagues, we showed that $\gamma$ HV68 latency enhanced experimental autoimmune encephalomyelitis (EAE) pathogenesis, a situation which paralleled the impact of coinfection with EBV and multiple sclerosis (MS) (3). Fourth, with Smiley and colleagues, we showed that $\gamma$ HV68 latency induced antibody-associated thrombocytopenia in mice, a situation analogous to that seen clinically in patients with chronic active EBV infection (14). The pathology was associated with viral latency and platelet-specific antibodies. These studies and others by diverse scientific groups illustrate the utility of the in vivo mouse $\gamma \mathrm{HV} 68$ model for enhancing our understanding of clinical consequences of EBV latency.

\section{Summary}

The mouse $\gamma$-herpesvirus provides an excellent in vivo model for the human $\gamma$-herpesviruses. My laboratory's efforts were focused on defining the immune control of latency to support developing vaccines that would prevent the establishment of latency and thus the onset of malignancies. Our work, of course, took place in the context of many other studies on $\gamma$-HV68 by multiple groups. This report is not meant to be a review of the field-just to report our contributions, and how they all began with my interaction with Peter Doherty.

In conclusion, Peter was an inspiration to my career-not only in terms of promoting my interest in viruses but also in his approach to science. He was always interested in promoting the science and cooperation between scientists, without worrying too much about competition. Of course, his key contribution to science was the idea of MHC restriction, which fundamentally altered the way we think about $\mathrm{T}$ cell immunity. I was at St. Jude when it was announced that Peter and his early colleague Rolf Zinkernagel were awarded the Nobel Prize. I can think of no one better deserving of a Nobel Prize.

\section{Acknowledgments}

The author thanks all the people in her laboratory over the years who carried out all the experiments mentioned here.

\section{Author Disclosure Statement}

No competing financial interests exist.

\section{Funding Information}

The research was supported by ALSAC, St Jude Children's Research Hospital, Trudeau Institute, and various NIH grants.

\section{References}

1. Barton ES, White DW, Cathelyn JS, et al. Herpesvirus latency confers symbiotic protection from bacterial infection. Nature 2007;447:326-329.

2. Barton ES, White DW, and Virgin HW. Herpesvirus latency and symbiotic protection from bacterial infection. Viral Immunol 2009;22:3-4.

3. Casiraghi C, Shanina I, Cho S, et al. Gammaherpesvirus latency accentuates EAE pathogenesis: relevance to Epstein-Barr virus and multiple sclerosis. PLoS Pathog 2012;8:e1002715.

4. Coppola MA, Flano E, Nguyen P, et al. Apparent MHCindependent stimulation of CD8+ $\mathrm{T}$ cells in vivo during latent murine gammaherpesvirus infection. J Immunol 1999; 163:1481-1489.

5. Evans AG, Moser JM, Krug LT, et al. A gammaherpesvirussecreted activator of Vbeta4+ CD8+ T cells regulates chronic infection and immunopathology. J Exp Med 2008;205:669684.

6. Flano E, Husain SM, Sample JT, et al. Latent murine gamma-herpesvirus infection is established in activated B cells, dendritic cells, and macrophages. J Immunol 2000; 165:1074-1081.

7. Flano E, Jia Q, Moore J, et al. Early Establishment of gamma-herpesvirus latency: implications for immune control. J Immunol 2005;174:4972-4978.

8. Flano E, Kim IJ, Woodland DL, et al. gamma-herpesvirus latency is preferentially maintained in splenic germinal center and memory B cells. J Exp Med 2002;196:1363-1372.

9. Flano E, Woodland DL, and Blackman MA, Requirement for $\mathrm{CD} 4+\mathrm{T}$ cells in Vbeta4+CD8+ $\mathrm{T}$ cell activation associated with latent murine gammaherpesvirus infection. J Immunol 1999;163:3403-3408. 
10. Flano E, Woodland DL, Blackman MA, et al. Analysis of virus-specific $\mathrm{CD} 4(+) \mathrm{T}$ cells during long-term gammaherpesvirus infection. J Virol 2001;75:7744-7748.

11. Freeman ML, Burkum CE, Cookenham T, et al. CD4 T cells specific for a latency-associated gamma-herpesvirus epitope are polyfunctional and cytotoxic. J Immunol 2014; 193:5827-5834.

12. Freeman ML, Burkum CE, Jensen MK, et al. gammaHerpesvirus reactivation differentially stimulates epitopespecific CD8 T cell responses. J Immunol 2012;188:38123819.

13. Freeman ML, Burkum CE, Lanzer KG, et al. Cutting edge: activation of virus-specific CD4 T cells throughout gammaherpesvirus Latency. J Immunol 2011;187:6180-6184.

14. Freeman ML, Burkum CE, Lanzer KG, et al. Gammaherpesvirus latency induces antibody-associated thrombocytopenia in mice. J Autoimmun 2013;42:71-79.

15. Freeman ML, Burkum CE, Woodland DL, et al. Importance of antibody in virus infection and vaccine-mediated protection by a latency-deficient recombinant murine gammaherpesvirus-68. J Immunol 2012;188:1049-1056.

16. Freeman ML, Burkum CE, Yager EJ, et al. De novo infection of B cells during murine gammaherpesvirus-68 latency. J Virol 2011;85:10920-10925.

17. Freeman ML, Lanzer KG, Cookenham T, et al. Two kinetic patterns of epitope-specific CD8 T-cell responses following murine gammaherpesvirus 68 infection. J Virol 2010;84: 2881-2892.

18. Hardy CL, Flano E, Cardin RD, et al. Factors controlling levels of CD8+ T-cell lymphocytosis associated with murine gammaherpesvirus infection. Viral Immunol 2001;14:391-402.

19. Hardy C, Lu L, Nguyen $P$, et al. Identification of quantitative trait loci controlling activation of TRBV4 CD8+ T cells during murine g-herpesvirus-induced infectious mononucleosis. Immunogenetics 2001;53:395-400.

20. Hardy CL, Silins SL, Woodland DL, et al. Murine gammaherpesvirus infection causes V(beta)4-specific CDR3- restricted clonal expansions within CD8(+) peripheral blood T lymphocytes. Int Immunol 2000;12:1193-1204.

21. Husain SM, Usherwood EJ, Dyson H, et al. Murine gammaherpesvirus M2 gene is latency-associated and its protein a target for CD8(+) T lymphocytes. Proc Natl Acad Sci U S A 1999;96:7508-7513.

22. Jia Q, Freeman ML, Yager EJ, et al. Induction of protective immunity against murine gammaherpesvirus 68 infection in the absence of viral latency. J Virol 2010;84:2453-2465.

23. Kayhan B, Yager EJ, Lanzer K, et al. A replicationdeficient murine g-herpesvirus blocked in late viral gene expression can establish latency and elicit protective cellular immunity. J. Immunol 2007;179:8392-8402.

24. Kim I-J, Flano E, Woodland DL, et al. Antibody-mediated control of persistent gamma-herpesvirus infection. J Immunol 2002;168:3958-3964.

25. Kim I-J, Flano E, Woodland DL, et al. Maintenance of long term gamma-herpesvirus B cell latency is dependent on CD40-mediated development of memory B cells. J Immunol 2003; 171:886-892.

26. Liu L, Flano E, Usherwood EJ, et al. Lytic cycle T cell epitopes are expressed in two distinct phases during MHV68 infection. J Immunol 1999;163:868-874.

27. Liu L, Usherwood EJ, Blackman MA, et al. T-cell vaccination alters the course of murine herpesvirus 68 infection and the establishment of viral latency in mice. J Virol 1999; 73:9849-9857.
28. Macrae AI, Usherwood EJ, Husain SM, et al. Murid herpesvirus 4 strain $68 \mathrm{M} 2$ protein is a B-cell-associated antigen important for latency but not lymphocytosis. J Virol 2003;77:9700-9709.

29. Martinez-Guzman D, Rickabaugh T, Wu T-T, et al. Transcription program of murine gammaherpesvirus 68. J Virol 2003; 77:10488-10503.

30. Nash AA, and Sunil-Chandra NP. Interactions of the murine gammaherpesvirus with the immune system. Curr Opin Immunol 1994;6:560-563.

31. Quezada SA, Simpson TR, Peggs KS, et al. Tumor-reactive CD4(+) T cells develop cytotoxic activity and eradicate large established melanoma after transfer into lymphopenic hosts. J Exp Med 2010;207:637-650.

32. Rickinson AB, and Lane PJL. Epstein-Barr virus: co-opting B-cell memory and migration. Curr Biol 2000;10:R120R123.

33. Stevenson PG, Cardin RD, Christensen JP, et al. Immunological control of a murine gammaherpesvirus independent of CD8+ T cells. J Gen Virol 1999;80:477-483.

34. Thorley-Lawson DA, and Babcock GJ. A model for persistent infection with Epstein-Barr virus: the stealth virus of human B cells. Life Sci 1999;65:1433-1453.

35. Tripp RA, Hamilton-Easton AM, Cardin RD, et al. Pathogenesis of an infectious mononucleosis-like disease induced by a murine gamma-herpesvirus: role for a viral superantigen? J Exp Med 1997;185:1641-1650.

36. Usherwood EJ, Roy DJ, Ward K, et al. Control of gammaherpesvirus latency by latent antigen-specific CD8(+) $\mathrm{T}$ cells. J Exp Med 2000;192:943-952.

37. Usherwood EJ, Ward KA, Blackman MA, et al. Latent antigen vaccination in a model gammaherpesvirus infection. J Virol 2001;75:8283-8288.

38. Virgin HW, Latreille P, Wamsley $\mathrm{P}$, et al. Complete sequence and genomic analysis of murine gammaherpesvirus 68. J Virol 1997;71:5894-5904.

39. Woodland DL, Usherwood EJ, Liu L, et al. Vaccination against murine g-herpesvirus infection. Viral Immunol 2001;14:217-226.

40. Wu T-T, Blackman MA, and Sun R. Prospects of a novel vaccination strategy for human gamma-herpesviruses. Immunol Res 2010;48:122-146.

41. Xie Y, Akpinarli A, Maris C, et al. Naive tumor-specific CD4(+) T cells differentiated in vivo eradicate established melanoma. J Exp Med 2010;207:651-667.

42. Yager EJ, Ahmed M, Lanzer K, et al. Age-associated decline in $\mathrm{T}$ cell repertoire diversity leads to holes in the repertoire and impaired immunity to influenza virus. J Exp Med 2008;205:711-723.

43. Yager EJ, Smiley ST, and Blackman MA. Response to Letter. Viral Immunol 2009;22:5-6.

44. Yager EJ, Szaba FM, Kummer LW, et al. gammaHerpesvirus-induced protection against bacterial infection is transient. Viral Immunol 2009;22:67-72.

Address correspondence to: Dr. Marcia A. Blackman Trudeau Institute 154 Algonquin Avenue Saranac Lake, NY 12983

E-mail: mblackman@trudeauinstitute.org 